\title{
Deflections Estimation of Light Wood-framed Shear Walls Without Hold-Downs
}

\author{
Jianan $\mathrm{LI}^{1}$, Ling Wang ${ }^{1 *}$, Xueying $\mathrm{Hu}^{2}$, Tao $\mathrm{Liu}^{2}$ \\ ${ }^{1}$ School of Civil and Transportation Engineering, Hebei University of Technology, Tianjin 300401, China \\ ${ }^{2}$ Tianjin Architectural Design Institute, Tianjin 300401, China
}

\begin{abstract}
In the structural design of light wood structures in recent years, people have paid more and more attention to estimating the lateral deformation of buildings. In order to better estimate the lateral deformation of the balsa shear wall without hold-downs, this paper carried out the lateral loading test of the wood shear wall and the monotonic loading test of the nail joint. A formula for lateral load-deformation of nail nodes suitable for engineering entities is proposed. A method for calculating the lateral deformation of wood shear walls without hold-downs is provided. The method is based on the formula for lateral deformation of light-weight timber structure shear walls in China's Code for Design of Timber Structures (GB50005-2017) ${ }^{[1]}$. This method complements the domestic wood structure regulations very well.
\end{abstract}

\section{Introduction}

The light wood structure building has formed an industrialized system in the West very early, and it started relatively late in China. Since the 21 st century, China has vigorously promoted the development of green and energy-saving buildings including light wood structures and prefabricated buildings. The timber structure shear wall is an important component of the lateral resistance system of light timber structure buildings. The cladding panel is connected with the wall stud column made of specification material mainly by nails, and the top and bottom beam slabs are arranged at the upper and lower ends of the wall stud column. In engineering, hold-downs are generally to resist strong wind and seismic forces. However, many traditional walls are more convenient and flexible in processing and production. In order to reduce the cost and process, the wall generally does not use hold-downs, and is only fixed to the foundation structure by nails or shear bolts. There are no hold-downs at the doors and windows of some wooden shear walls.

China's "Wood Structure Design Code (GB50005-2017) [1] focuses on the formulation of relevant Canadian and American wood structure codes. Regarding the light wood structure wall panels, the code focuses on the wall structure design and mechanical calculations. The displacement calculation is mainly aimed at the wall using hold-downs, and it is not possible to predict the lateral deformation of the light wood shear wall without hold-downs.CSA-O86-01-Engineering Design in Wood puts forward the corresponding lateral deformation formula, which was developed by $\mathrm{Ni}$ and Karacabeyli ${ }^{[2-3]}$ on a large number of shear walls without hold-downs. Based on the experimental research, a deformation reduction formula is proposed. The formulas for estimating the deformation of timber shear walls proposed by the corresponding timber structure codes of China, the United States and New Zealand are about regular walls with anchors added, and there is no direct displacement prediction formula for traditional (no hold-downs) walls. Domestic Zhang Shengdong [4] extended the four-term deformation formula adopted by the United States Uniform Building Code. On the basis of proposing a new nail joint load-deformation formula, considering the cladding and bottom beam slab The nail joint resists the pull-up force, and the formula that can calculate the lateral deformation of the wood structure shear wall without hold-downs is given. However, the deformation effect caused by the connection between the wall studs and the bottom beam slab nails is not well considered. The specific effect of the transverse bracing on the initial stiffness and lateral deformation of the wall is not known.

In this paper, the lateral deformation test of the wood shear wall without corner anchoring is carried out. At the same time, the horizontal monotonic loading test of six sets of nail joints and the pullout analysis of nail joints are carried out. Hope to give a calculation method for the lateral deformation of wood shear walls without corner anchors. The proposed method is based on the Chinese Code for Design of Timber Structures (GB50005-2017) ${ }^{[1]}$ the lateral displacement formula of light-weight timber structure shear walls. The method can predict the lateral deformation of the shear wall without corner anchors to the medium load level (design load), but it is not the whole process.

wlark@sina.com, 501980601@qq.com 


\section{Lateral performance test of shear wall}

\subsection{Test overview}

In order to more intuitively explore the lateral deformation of wood shear walls without hold-downs, a lateral force test of light wood shear walls was carried out at the Structural Experiment Center of the Hongqiao
Campus of Hebei University of Technology. The wall specimens are divided into 3 groups with 6 sides in total. The two test pieces in each group have exactly the same structure and are loaded monotonically. The influence of hold-downs and transverse bracing on the ultimate bearing capacity and lateral stiffness of light-weight timber shear walls is mainly considered. The parameters of the specimens are shown in Table 1 .

Table 1. Specimen grouping

\begin{tabular}{cccccc}
\hline Specimen size/m & $\begin{array}{c}\text { Specimen } \\
\text { number }\end{array}$ & $\begin{array}{c}\text { Bone column } \\
\text { spacing/mm }\end{array}$ & Hold-downs & Cross bracing & $\begin{array}{c}\text { nail } \\
\text { spacing/mm }\end{array}$ \\
\hline \multirow{3}{*}{$2.44 * 2.44$} & A1/A2 & 400 & Yes & No & $300 / 150$ \\
\cline { 2 - 6 } & B1/B2 & 400 & No & No & $300 / 150$ \\
\cline { 2 - 6 } & C1/C2 & 400 & No & Yes & $300 / 150$ \\
\hline
\end{tabular}

The cladding is an OSB board imported from Canada with a thickness of $15 \mathrm{~mm}$. The cross-section size of the wall bone is $38 \times 140 \mathrm{~mm}$. The top beam is double-layered, and the bottom beam is single-layer. The materials and dimensions and the wall studs are all SPF specifications. The walls are connected uniformly with paper row nails with a diameter of $3.15 \mathrm{~mm}$ and a length of $75 \mathrm{~mm}$. The shear wall specimen and loading device are shown in Figure 1.

The monotonic loading test refers to the ASTM E564 ${ }^{[5]}$ standard, and the entire loading process is divided into four stages. The first is the pre-loading stage. Load to $10 \%$ of the wall's ultimate load (pre-estimated), hold the load for 5 minutes, and then unload to 0 . After completely unloading for 5 minutes, the meter value is cleared to enter the formal loading. The formal load is loaded to $1 / 3$ of the ultimate load of the wall and then unloaded to 0 , and then loaded to $2 / 3$ to unload to 0 , and finally loaded until the test load drops to $80 \%$ of the ultimate load or the specimen is seriously damaged.

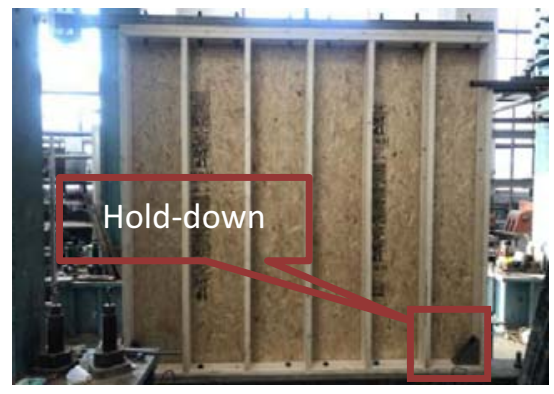

Fig.1 Specimen loading device

\subsection{Analysis of test results}

\subsubsection{The failure mode of the wall}

A specimen can fully exert the function of each component in the monotonous loading process. The damage is mainly concentrated on the separation of the panel and the wall studs, the pulling out and yielding of the nails at the bottom beam and the torsion between the panels. The wall studs on the edge of the loading end are pulled up slightly, and the pulling up amplitude is much lower than that of the $\mathrm{B}$ and $\mathrm{C}$ specimens. The second wall stud at the loading end moves up the most. The overall deformation of test piece $A$ is mainly the deformation of the wooden frame. With the increase of the load, the overall deformation is twisted from a rectangle to a parallelogram. The cladding panel is twisted with the bottom corner of the far loading end as the fulcrum, which is more obvious than the $\mathrm{B}$ and $\mathrm{C}$ specimens. The damage of specimens $\mathrm{B}$ and $\mathrm{C}$ without hold-downs is mainly the pulling up of the wall studs. The damage of the edge studs is the most obvious. The nails are completely pulled out from the bottom beam, and the bottom beam is connected to the cladding. Bend and yield. The overall deformation is mainly the separation deformation between the cladding panel, the top beam slab, the wall column and the bottom beam slab. During the loading process, the relative displacement and torsion between the wall studs and the cladding panels of specimen $\mathrm{C}$ and the two cladding panels were the smallest, followed by specimen B and specimen A the largest. The role of the superstructure is not fully exerted, and the destructive bone column uplift damage occurs. But at the same time, the lateral displacement caused by the upper failure is mainly caused by this failure mode.

The above-mentioned destruction phenomenon can be seen in Figure 2.

During the test, it can be found that during the push-pull process of the wood shear wall without hold-downs, the pull-up force generated by the wall stud column makes the wall stud column, the cladding panel and the bottom beam slab reach the bearing limit. Damage occurs first, and a large displacement occurs. The focus of the calculation of lateral deformation is to obtain the relationship between load and displacement at the failure site, and the change of lateral displacement caused by the uplift of the wall stud is the most critical. 


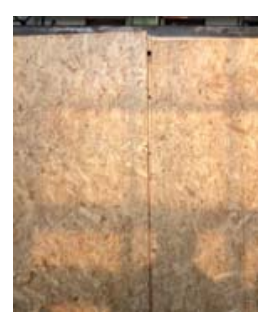

(a)Panel torsion failure

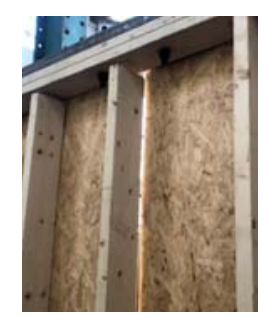

(b) The wall column is separated

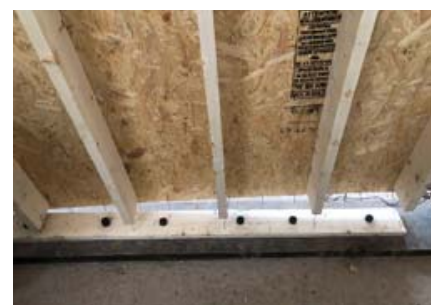

(c) The wall bone column was pulled out from the face plate

Fig2.Shear wall failure mode

the wall without hold-downs Deformed.

\subsubsection{Mechanical analysis of the wall}

As shown in Figure.3, the ultimate bearing capacity of specimen $\mathrm{A}$ is increased by $48.24 \%$ and $52.95 \%$ compared with specimens $\mathrm{B}$ and $\mathrm{C}$, and the ultimate displacement is increased by $96.50 \%$ and $53.12 \%$, respectively. The setting of hold-downs significantly improves the ultimate load and ultimate displacement of the wall. The ultimate load of specimen B and specimen $\mathrm{C}$ without hold-downs is not much different, and the ultimate displacement of specimen $\mathrm{C}$ is increased by $28.33 \%$ compared with specimen B. The added cross brace does not enhance the anti-side ability, but it effectively increases the limit displacement.

Considering the calculation of the lateral deformation of the wooden shear wall, the theoretical relationship between the initial stage load and displacement is analyzed, and the load-displacement curve (the first cycle envelope of low-cycle repeated loading) is defined between the origin and the $40 \%$ ultimate load point The slope of the secant line is the lateral stiffness of the specimen in the elastic phase.

The lateral stiffness of specimen A and specimen B in the elastic phase are close, and the anchor has little effect on this parameter. However, the elastic lateral stiffness of specimen $\mathrm{C}$ is $34.2 \%$ lower than that of specimen B. Although the addition of cross braces improves the integrity of the specimen, it does not enhance the lateral stiffness of the elastic stage. The main consideration is that the failure mode of the wood shear wall without anchors is mainly the uplift of the edge wall bone column, and the lateral deformation is mainly controlled by the uplift. The addition of transverse bracing can not effectively restrain the separation of the bottom beam plate and the bone column or the cladding panel, which enhances the local rigidity, but enhances the ductility of the structure by improving the integrity, and the ultimate displacement is increased.

The analysis shows that the key point should be to express the mathematical relationship between the shear resistance, pull-out force and displacement of the nail node to characterize the deformation of the up-lift of the wall bone column, so as to deduce the lateral direction of

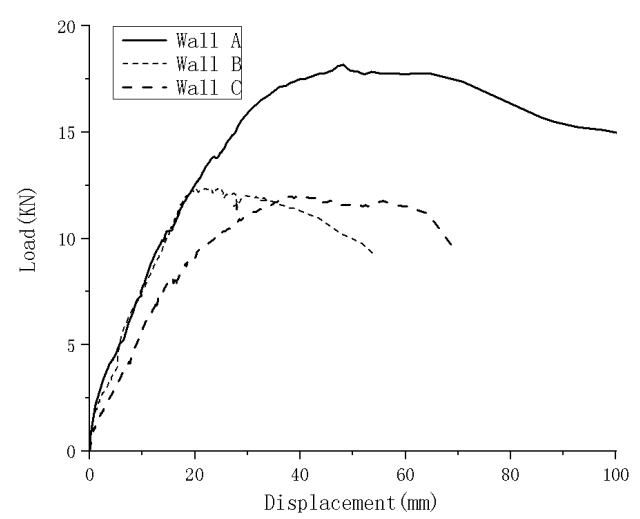

Fig3.Specimen load-displacement curve

\section{Nail node load-deformation relationship}

\subsection{Nail joint under shear}

Nail joints have a key influence on the lateral performance of wood shear walls ${ }^{[6][7]}$. Aiming at the above-mentioned wooden shear wall, using the same material and manufacturing process, ten panel nail joint specimens were made for monotonic loading test. The test was carried out in the Civil Engineering Experimental Teaching Center of Hebei University of Technology. The test was loaded with reference to ASTM D1761-8 $8^{[8]}$. The MTS universal testing machine was selected to perform monotonous uniform loading at a speed of $3 \mathrm{~mm} / \mathrm{min}$. The loading was stopped until the load-bearing capacity of the specimen dropped to $80 \%$ of the maximum load-bearing capacity or the OSB board and SPF specification material were obviously damaged. The photo of the loading device is shown in Figure 4.

Canadian test material inlet OSB board thickness of $15 \mathrm{~mm}$; Canadian SPF lumber inlet cross-sectional dimensions of $38 \mathrm{~mm} \times 140 \mathrm{~mm}$; staple paper discharge diameter of $3.15 \mathrm{~mm}$, a length of $75 \mathrm{~mm}$. The detailed dimensions of the test piece are shown in Figure 5. 


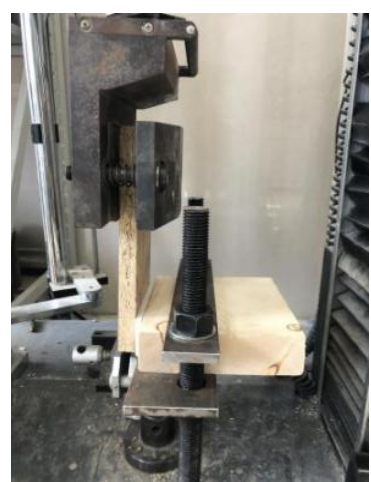

Fig.4.Loading device

The test result is shown in Fig. 6, which is quite different from the lateral load-deformation formula of the nail joint recommended by CSA-O86. The main reason may be that the test methods used are different, and the paper row of nails shot by the nail gun is used. Compared with the nails with complicated surfaces such as the twist nails that are driven by hand, their shear resistance and pullout resistance are better. low.

According to the test results, and refer to CSA-O86-01-Engineering Design in Wood nail node formula:

$$
\Delta=0.5 \mathrm{~d} K_{\mathrm{m}}\left(F / \mathrm{n}_{\mathrm{u}}\right)^{2.6}\left(F<\mathrm{n}_{\mathrm{u}} / 3\right)
$$
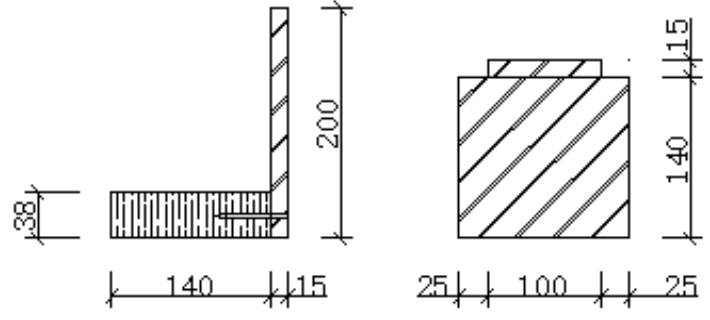

Fig.5.Detail of the specimens

It is recommended that the lateral load-deformation formula of the nail joint formed by this kind of wood and nail adopts formula 2 :

$$
\Delta=1.9 \mathrm{~d} K_{\mathrm{m}}\left(F / \mathrm{n}_{\mathrm{u}}\right)^{1.45}\left(F<\mathrm{n}_{\mathrm{u}} / 3\right)
$$

Where $\Delta$ is the lateral deformation of the nail node, $\mathrm{mm} ; d$ is the diameter of the nail, $\mathrm{mm} ; K_{m}$ is the creep factor when considering the load; $F$ is the design load of each nail, $\mathrm{N} ; n_{u}$ is each Nail carrying capacity, $\mathrm{N}$.

The load displacement of the test nail joint, the Canadian timber structure code nail joint and the theoretical formula is shown in Figure 6.

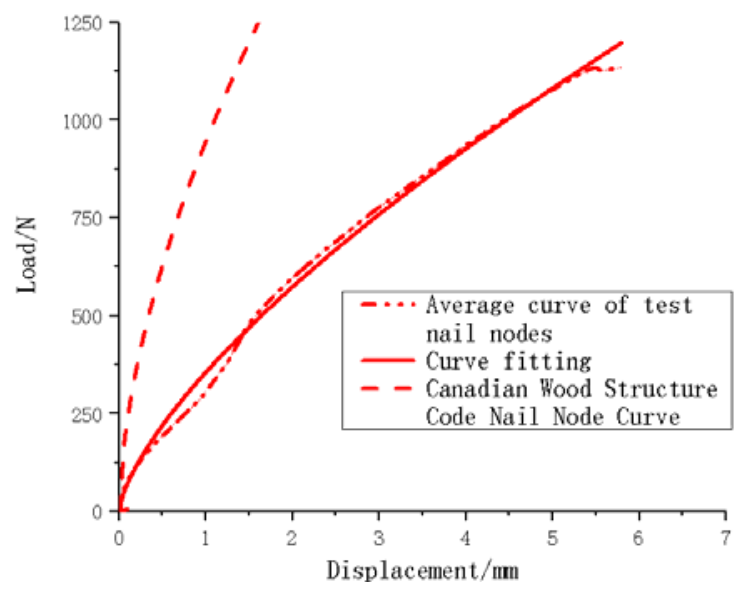

Fig.6. Comparisons of load-nail slip curves of nailed joint with test nails or CSA common nails

\subsection{Nail node pulled out}

The main factors that determine the pull-out resistance are the density of the base material $\rho$, the diameter $D$ of the nail and the penetration depth $L$ of the nail. The general formula for calculating nail pull resistance is:

$$
P=K G^{\mathrm{a}} D L
$$

Wherein $K$ is a constant of a load over a long period, the water content-adjusted changes security, $a$ is the density index, $G$ is the absolute dry wood density, $\mathrm{kgm}^{-3}$; $D$ is the diameter of the nail, $\mathrm{mm} ; L$ is the driving depth, $\mathrm{mm}$. North American wood structure Specification (NDS) unified the $K$ value nail design formula was changed to 47.6 from 54.12, still in use. For the test node staple paper discharge connected staples, pullout resistance can be empirical formula:

$$
P=47.6 G^{2.5} \mathrm{DL}
$$

\section{Formula derivation}

In China's Code for Design of Timber Structures(GB50005-2017) $)^{[1]}$, the formula for lateral deformation of a regular shear wall is:

$$
\Delta=\frac{V H_{W}^{3}}{3 E I}+\frac{M H_{W}^{2}}{2 E I}+\frac{V H_{W}}{L K_{W}}+\frac{H_{W} d_{a}}{L}+\theta_{\mathrm{i}} \cdot H_{W}
$$

$\Delta$ is the total displacement of the top of the shear wall, $\mathrm{mm} ; V$ is the maximum shear value at the top of the shear 
wall, $\mathrm{N} ; M$ is the design value of the maximum shear force at the top of the shear wall, $\mathrm{N} ; H_{w}$ is the height of the shear wall, $\mathrm{mm}$; $I$ is the shear force Wall conversion moment of inertia, $\mathrm{mm}^{4} ; E$ is the elastic modulus of wall members, $\mathrm{N} / \mathrm{mm} 2 ; L$ is the height of the shear wall, $\mathrm{mm}$; $K_{w}$ is the shear stiffness of the shear wall, N/mm; $d_{a}$ is the deformation caused by the hold-downs , mm; $\theta_{i}$ is the corner of the i-th layer of shear wall.

According to the specification, during the stress process of the balsa shear wall, the side shift comes from five parts: the wall bending deformation caused by shear and bending moment, the wall shear deformation caused by the shear force, the deformation caused by the corner between layers, and the wall corner. Deformation caused by anchors.In the balsa shear wall without hold-downs, the lateral displacement caused by the uplift of the load-end wall studs replaces the deformation of the anchors, giving $d_{a}$ new meaning. That is to say, the calculation of the side displacement of the balsa shear wall without hold-downs can not change the calculation content of the other items in the formula, only redefine $d_{a}$, that is, calculate the load-displacement relationship of the load-end wall stud.

It is assumed that the pull-up force caused by the horizontal load is resisted by a row of nail nodes connecting the cladding slab and the bottom beam slab, as well as the nail nodes of the wall studs and the bottom beam slab.

It is also assumed that the vertical deformation of the nail node along the bottom beam slab caused by the pull-up force is linearly distributed (the final deformation of the nail node is actually a combination of the vertical deformation caused by the pull-up force and the relative rotation of the cladding panel and the frame. ). The function of nailing nodes along the bottom beam or base board is continuous.

Suppose it is the nail density along the bottom beam slab or the base plank, $d_{a}$ is the vertical deformation of the nail node at the right end of the wall. According to the above assumption, the vertical deformation of the nail node at a distance $\mathrm{x}$ from the bottom left end of the wall is:

$$
\Delta=x d_{a} / L_{w}
$$

Substitute the lateral load-deformation formula of the nail node:

$$
\Delta=1.9 \mathrm{~d} K_{\mathrm{m}}\left(F / \mathrm{n}_{\mathrm{u}}\right)^{1.45}\left(F<\mathrm{n}_{\mathrm{u}} / 3\right)
$$

The shear resistance of the nail is:

$$
F_{j}=n_{u} \sqrt[1.45]{x d_{a} / 1.9 d L_{w} K_{m}}
$$

Nail pull resistance:

$$
F_{b}=47.6 G^{2.5} d l
$$

Take the bending moment at point $\mathrm{B}$ to zero to get:

$$
v_{s} L_{W} H_{S}=\int_{0}^{L_{W}} \rho d x\left(F_{j}+F_{b}\right) x
$$

After the calculation is simplified, we can get:

$$
d_{a}=\frac{1.9 d K_{m}\left(v_{s} H_{s} S_{n}-23.8 L_{w} G^{2.5} d l\right)^{1.45}}{n_{u} L_{w}^{0.77}}
$$

The vertical displacement of the marginal bone column can be predicted by $d_{a}$. Incorporating $d_{a}$ into formula 5 , the wall deformation can be calculated more accurately.

\section{Conclusion}

In this paper, the following conclusions are obtained through the experimental research, analysis and calculation of light wood structure walls and joints:

(1) The lateral displacement of wood shear walls without hold-downs is mainly controlled by the uplift of the wall studs;

(2) If the vertical plank wood shear wall lacks hold-downs or upper load to control the uplift of the wall studs, it will not be able to fully play the role of the upper parts. Even if the horizontal bracing is added to enhance the integrity of the wall frame, it will not enhance the bearing capacity;

(3) Based on the test results and referring to the nail node formula of CSA-O86-01-Engineering Design in Wood, a nail node lateral load-deformation formula is proposed, which is applicable to the load deformation of the materials used in the test in this article;

(4) On the basis of the formula for the lateral deformation of light timber shear walls in China's Code for Design of Timber Structures (GB50005-2017), it is recommended to give $d_{a}$ a new meaning. In this way, the purpose of calculating the displacement of wood shear walls without hold-downs can be achieved.

\section{Acknowledgments}

Thanks to the support of Tianjin Science and Technology Plan Project: Key Technology Research and Application of Prefabricated Timber Structure System (18ZXAQSF00100).

\section{References}

1. Wood structure design code: GB50005-2017 [S]. 2018 edition. Beijing: China Construction Industry Press, 2018.

2. Ni C, Karacabeyli E. Effect of overturning restraint on performance of shear walls[C]. 2000 World Conference on Timber Engineering. Whistler Resort:[s.n.],2000: 2-3-1.

3. Ni C, Karacabeyli E. Capacity of shear wall segments without hold-downs[J]. Wood Design Focus, 2002, 12(2): 10.

4. Shengdong Zhang,Karacabeyli Erol.Calculation of Lateral Deformation of Shear Walls with Wood Structures Without Anti-overturning Anchors[J]. Journal of Tongji University (Natural Science Edition), 2008, (03):299-303.

5. ASTM-E564-06(2012) Standard Practice for Static Load Test for Shear Resistance of Framed Walls for Buildings [S]. Pennsylvania, USA: ASTM international, 2012. 
6. Guangyang Xia. Experimental study on new balsa wall panel-keel joints [J]. Building Structure, 2018, 48 (10): 61-65

7. Weibo Dong. Experimental study on the influence of different nails on the strength of light-weight wooden structure nail joints [J]. Building Structure, 2019, 49: 268-272[6]

8. Standard test method for determining bending yield momen of nails:ASTM-F1575-03 [S] .Pennsylvani: ASTM International, 2003. 